\title{
AN INTRODUCTION OF KRILL HERD ALGORITHM FOR ENGINEERING OPTIMIZATION
}

\author{
Amir H. GANDOMIa ${ }^{\mathrm{a}}$ Amir H. ALAVI ${ }^{\mathrm{b}}$ \\ ${ }^{a}$ Department of Civil Engineering, The University of Akron, Akron, OH 44325, USA \\ ${ }^{b}$ Department of Civil and Environmental Engineering, Michigan State University, East Lansing, MI, 48824, USA
}

Received 04 Mar 2013; accepted 26 Apr 2013

\begin{abstract}
A new metaheuristic optimization algorithm, called Krill Herd (KH), has been recently proposed by Gandomi and Alavi (2012). In this study, KH is introduced for solving engineering optimization problems. For more verification, $\mathrm{KH}$ is applied to six design problems reported in the literature. Further, the performance of the KH algorithm is compared with that of various algorithms representative of the state-of-the-art in the area. The comparisons show that the results obtained by $\mathrm{KH}$ are better than the best solutions obtained by the existing methods.
\end{abstract}

Keywords: Krill Herd, engineering design, global optimization, metaheuristic algorithm.

\section{Introduction}

The engineering optimization problems are commonly non-linear. They have different design variables under complex constraints. These constraints can be considered as simple bounds or as non-linear relationships. The non-linearity of such optimization problems often leads to a multimodal response landscape (Yang 2010; Gandomi et al. 2013a). Consequently, only global optimization algorithms can be used to obtain optimal solutions. Metaheuristic algorithms can be defined as upper level general methodologies. They can be used as guiding strategies in designing underlying heuristics to handle engineering optimization problems (Gandomi et al. 2013a; Talbi 2009). The main characteristics of metaheuristics are: (1) intensification and (2) diversification (Yang 2009). Intensification searches around the current best solutions and selects the best candidates or solutions. Diversification guarantees that the algorithm can explore the search space more efficiently.

The main goals of developing modern metaheuristic methods are to solve problems faster, to solve large problems, and to obtain robust algorithms (Talbi 2009). The most typical types of metaheuristics are genetic algorithms (GA) and particle swarm optimization (PSO). The efficiency of metaheuristic algorithms is related to the fact that they imitate the best features in nature.

Krill Herd (KH) algorithm is a new metaheuristic search algorithm. This algorithm is based on simulating the herding behaviour of krill individuals using a
Lagrangian model and crossover. This algorithm is developed by Gandomi and Alavi (2012) and the preliminary studies show that it is very promising and could outperform existing algorithms (Gandomi et al. 2013c, 2013d). In this paper, the KH algorithm is further validated against various engineering optimization problems. The introduced search strategy is compared with other popular optimization algorithms. Finally, the unique features of $\mathrm{KH}$ are discussed and topics for further studies are proposed.

\section{Krill Herd algorithm}

\subsection{Lagrangian model of the krill herding}

Predators remove individuals, reduce of the average krill density, and distance the krill swarm from the food location. Therefore, predation can be considered as the initialization of the optimization algorithm. The fitness of each individual in the natural system, is supposed to be the distances from the food centre and the highest density of the krill swarm (Gandomi, Alavi 2012).

Hofmann et al. (2004) proposed three effective factors of individual krill position as:

i. movement induced by other krill individuals;

ii. foraging activity; and

iii.random diffusion,

which can be formulated during the time and for $\mathrm{n}$ dimensional space, using the following Lagrangian model:

$$
\frac{d X_{i}}{d t}=N_{i}+F_{i}+D_{i}
$$

Corresponding author: Amir H. Gandomi

E-mail:a.h.gandomi@gmail.com 
where $N_{i}, F_{i}$ and $D_{i}$ are respectively the motions i, ii and iii.

\subsubsection{Motion induced by other krill individuals}

For the $i^{\text {th }}$ krill individual, the induced motion is formulated as:

$$
N_{i}^{\text {new }}=N^{\text {max }} \alpha_{i}+\omega_{n} N_{i}^{\text {old }}
$$

and

$$
\alpha_{i}=\alpha_{i}^{\text {local }}+\alpha_{i}^{\text {target }},
$$

where $N^{\max }$ is the maximum induced speed, $\alpha_{i}$ is the direction of motion, $\omega_{n}$ is the inertia weight, $N_{i}^{\text {old }}$ is the last induced motion, $\alpha_{i}^{\text {local }}$ is the local effect provided by the neighbors and $\alpha_{i}^{\text {target }}$ is the target direction effect provided by the best krill individual. According to Hofmann et al. (2004), $N^{\max }$ considered to be equal to $0.01\left(\mathrm{~ms}^{-1}\right)$.

The effect of the neighboursin a krill movement individual can be formulated as (Gandomi, Alavi 2012):

$$
\begin{gathered}
\alpha_{i}^{\text {local }}=\sum_{j=1}^{N N} \hat{K}_{i, j} \hat{X}_{i, j} ; \\
\hat{X}_{i, j}={\frac{X_{j}-X_{i}}{\left\|X_{j}-X_{i}\right\|+\varepsilon} ;}^{\hat{K}_{i, j}}=\frac{K_{i}-K_{j}}{K^{\text {worst }}-K^{\text {best }}},
\end{gathered}
$$

where $K^{\text {worst }}$ and $K^{\text {best }}$ are, respectively, the worst and the best fitness values of the krill individuals; $K_{i}$ represents the fitness value of the $i^{\text {th }}$ krill individual; $K_{j}$ is the fitness of $j^{\text {th }}$ neighbour and $j \in\{1,2, \ldots, N N\}$ and $X$ is the positions in the search domain. $\varepsilon$ is suggested to be a small number (Gandomi, Alavi 2012). In this study, this parameter is equal to $10^{-6}$.

For choosing a neighbour krill for the $i^{\text {th }}$ krill individual, a sensing distance $\left(d_{s, i}\right)$ is defined using:

$$
d_{s, i}=\frac{1}{5 N} \sum_{j=1}^{N}\left\|X_{i}-X_{j}\right\|,
$$

where $N$ is the number of the krill individuals and $i \in\{1,2, \ldots, N\}$. Based on this equation, if the distance of two krill individuals is less than sensing distance, they are neighbors (Gandomi, Alavi 2012). The effect of the best fitness krill into the $\mathrm{i}^{\text {th }}$ individual krill is formulated as:

$$
\alpha_{i}^{\text {target }}=C^{\text {best }} \hat{K}_{i, \text { best }} \hat{X}_{i, \text { best }},
$$

where, $C^{\text {best }}$ is an empirical effective coefficient as:

$$
C^{\text {best }}=2\left(\operatorname{rand}+\frac{I}{I_{\max }}\right),
$$

where rand is a uniform random value between 0 and $1, I$ and $I_{\max }$ are, respectively, the actual and maximum number of iterations (Gandomi, Alavi 2012).

\subsubsection{Foraging motion}

There are two main terms in the foraging motion, the food attraction and the previous krill experience, which can be formulated as follows (Gandomi, Alavi 2012):

$$
F_{i}=V_{f} \beta_{i}+\omega_{f} F_{i}^{\text {old }}
$$

and

$$
\beta_{i}=\beta_{i}^{\text {food }}+\beta_{i}^{\text {best }},
$$

where $V_{f}$ is the foraging speed, $\omega_{f}$ is the inertia weight, $F_{i}^{\text {old }}$ is the last foraging motion, $\beta_{i}^{\text {food }}$ is the food attraction and $\beta_{i}^{\text {best }}$ is the effect of the best fitness of the $\mathrm{i}^{\text {th }} \mathrm{krill}$ during its history. Foraging speed is taken $0.02\left(\mathrm{~ms}^{-1}\right)$ based on (Price 1989).

In each iteration, the centre of food of can be defined like centre of mass as follows:

$$
X^{\text {food }}=\frac{\sum_{\mathrm{i}=1}^{N} \frac{1}{K_{i}} X_{i}}{\sum_{i=1}^{N} \frac{1}{K_{i}}}
$$

and, the food attraction for the can be formulated as:

$$
\beta_{i}^{\text {food }}=C^{\text {food }} \hat{K}_{i, \text { food }} \hat{X}_{i, \text { food }},
$$

where $C^{\text {food }}$ is empirically defined as:

$$
C^{\text {food }}=2\left(1-\frac{I}{I_{\max }}\right) .
$$

The effect of the best fitness of the $i^{\text {th }}$ krill individual during the history is defined as:

$$
\beta_{i}^{\text {best }}=\hat{K}_{i, \text { best }} \hat{X}_{i, i b e s t} \text {, }
$$

where $K_{\text {ibest }}$ is the best previously visited position by the $i^{\text {th }}$ krill individual.

\subsubsection{Physical diffusion}

The physical diffusion is a random process which can be formulated as follows (Gandomi, Alavi 2012):

$$
D_{i}=D^{\max }\left(1-\frac{I}{I_{\max }}\right) \delta,
$$

where $D^{\max }$ is the maximum diffusion speed, and $\delta$ is the uniform random directional vector between -1 and 1. Based on the suggested values in Morin et al. (1988), $D^{\max } \in[0.002,0.010]\left(\mathrm{ms}^{-1}\right)$. 


\subsubsection{Motion process of the KH algorithm}

Using the three explained motions, the position vector of a krill individual during the time interval from $t$ to $t+\Delta t$ is formulated as (Gandomi, Alavi 2012):

$$
X_{i}(t+\Delta t)=X_{i}(t)+\Delta t \frac{d X_{i}}{d t}
$$

where $\Delta t$ can be obtained from:

$$
\Delta t=C_{t} \sum_{j=1}^{N V}\left(U B_{j}-L B_{j}\right)
$$

where $N V$ is the number of variables, $L B_{j}$ and $U B_{j}$ are lower and upper bounds of the $j^{\text {th }}$ variables, respectively, and $C_{t}$ is a constant number which is considered as 0.5 in this study.

\subsection{Crossover}

As it is evaluated in the original paper, crossover is an effective process in the $\mathrm{KH}$ algorithm. By generating a uniformly distributed random vector values between 0 and 1 , the $m^{\text {th }}$ component of $X_{i}, X_{i, m}$ is manipulated as (Gandomi, Alavi 2012):

$$
\begin{gathered}
x_{i, m}=\left\{\begin{array}{cc}
x_{r, m} & \text { rand }_{i, m}<C r \\
x_{i, m} & \text { else }
\end{array} ;\right. \\
C r_{i}=0.2 \widehat{\mathrm{K}}_{\mathrm{i}, \mathrm{best}}
\end{gathered}
$$

where $C r_{i}$ is crossover probability of the $i^{\text {th }}$ kril individual.

\subsection{Constraint handling}

In order to solve the problem simpler, nonlinear constraints in the penalty function approach might be collapsed with the cost function into a response functional. This results in transformation of the constrained optimization problem into an unconstrained optimization one. The following example clarifies the issue. Assuming that there are some nonlinear equality constraints $\phi_{i}$ and some inequality constraints $\psi_{j}$, the response functional $\prod$ can be defined as follows (Gandomi et al. 2012):

$$
\Pi\left(x, \mu_{i}, v_{j}\right)=f(x)+\sum_{i=1}^{M} \mu_{i} \phi_{i}^{2}(x)+\sum_{j=1}^{N} v_{j} \psi_{j}^{2}(x),
$$

where: $1 \leq \mu_{i}$ and $0 \leq v_{i}$. The coefficients of penalty terms should be large enough; their values may depend on the specific optimization problem. The contribution of any equality constraints function to the response functional $\prod$ is null but increases notably as soon as the constraint is violated. The same applies to inequality constraints when they become critical (Gandomi et al. 2011).

If integer/discrete design variables are involved in an optimization problem, the variable is rounded to the nearest integer/discrete value.

\section{Implementation and numerical experiments}

Engineering optimization problems are complex, sometimes even the optimal solutions of interest do not exist. In order to see how the $\mathrm{KH}$ algorithm performs, four standard engineering test problems are solved. It should be noted that because of the random nature of the $\mathrm{KH}$ algorithm, 50 trials with independent population initializations have been made to obtain a better conclusion of the performance.

\subsection{Case I. Tubular column design}

Figure 1 presents an example for designing a uniform column of tubular section to carry a compressive load $P=2500 \mathrm{kgf}$ at minimum cost (Rao 1996). The column is made of a material with a yield stress $\left(\sigma_{y}\right)$ of $500 \mathrm{kgf} / \mathrm{cm}^{2}$, a modulus of elasticity $(E)$ of $0.85 \times 10^{6} \mathrm{kgf} / \mathrm{cm}^{2}$, and a density $(\rho)$ equal to $0.0025 \mathrm{kgf} / \mathrm{cm}^{3}$. The length $(L)$ of the column is $250 \mathrm{~cm}$. The stress included in the column should be less than the buckling stress (constraint $g_{1}$ ) and the yield stress (constraint $g_{2}$ ). The mean diameter of the column is restricted between 2 and $14 \mathrm{~cm}$ (constraint $g_{3}$ and $g_{4}$ ), and columns with thickness outside the range $0.2-0.8 \mathrm{~cm}$ are not commercially available (constraint $g_{5}$ and $g_{6}$ ). The cost of the column includes material and construction costs (Hsu, Liu 2007). It is taken as the objective function. The optimization model of this problem is given as follows:

Minimize: $\quad f(d, t)=9.8 d t+2 d$.

Subject to:

$$
\begin{gathered}
g_{1}=\frac{P}{\pi d t \sigma_{y}}-1 \leq 0 \\
g_{2}=\frac{8 P L^{2}}{\pi^{3} E d t\left(d^{2}+t^{2}\right)}-1 \leq 0,
\end{gathered}
$$

where: $2 \leq d \leq 14$ and $0.2 \leq t \leq 0.8$.

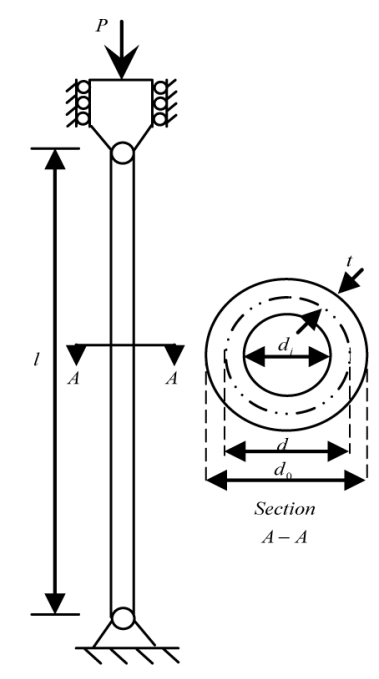

Fig. 1. The tubular column 
Table 1. Statistical results of the best model for tubular column design example

\begin{tabular}{lcccc}
\hline Best & Average & Median & Worst & S.D. \\
\hline 26.5314 & 26.5430 & 26.5378 & 26.6475 & 0.01798 \\
\hline
\end{tabular}

Table 2. Best solutions for the tubular column example

\begin{tabular}{lccccc}
\hline & $\begin{array}{c}\text { Rao } \\
(1996)\end{array}$ & $\begin{array}{c}\text { Hsu, Liu } \\
(2007)\end{array}$ & $\begin{array}{c}\text { Gandomi } \\
\text { et al. } \\
(2013 \mathrm{~b})\end{array}$ & $\begin{array}{c}\text { Rocha, } \\
\text { Fernandes } \\
(2009)\end{array}$ & $\begin{array}{c}\text { Present } \\
\text { Study }\end{array}$ \\
\hline$d$ & 5.44 & 5.4507 & 5.45139 & 5.451083 & 5.451278 \\
$T$ & 0.293 & 0.292 & 0.29196 & 0.29199 & 0.291957 \\
$g_{1}$ & -0.8579 & -0.00008 & -0.0241 & -0.00007 & 0.00000 \\
$g_{2}$ & $0.0026^{\mathrm{a}}$ & $0.1317^{\mathrm{a}}$ & -0.1095 & -0.00004 & -0.00004 \\
$F_{\min }$ & 26.5323 & 25.5316 & 26.53217 & 26.53227 & 26.5314 \\
\hline
\end{tabular}

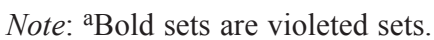

Table 1 illustrates the statistical results for the best objective value by $\mathrm{KH}$ when 10,000 searches havebeen done in each run. The statistical values presented in this table clearly show the proposed algorithm is successful in this case.

Table 2 compares the results obtained by $\mathrm{KH}$ with those reported in the literature (Rao 1996; Hsu, Liu 2007; Gandomi et al. 2013b; Rocha, Fernandes 2009). It can be observed from Table 2 that the best objective values by Rao (1996) and Hsu and Liu (2007) and are not feasible because the second constraint $\left(g_{2}\right)$ is violated. The Result of $\mathrm{KH}$ algorithm is also better than results obtained in Gandomi et al. (2013a), Rocha and Fernandes (2009). Therefore, KH algorithm provides better results than other algorithms.

\subsection{Case II. Three-bar truss design}

This case considers a 3-bar planar truss structure shown in Figure 2. This problem was first presented by Nowcki (1974) and it is one of the benchmark structural engineering problems (Gandomi, Yang 2011). The volume of a statically loaded 3-bar truss is to be minimized subject to stress $(\sigma)$ constraints on each of the truss members. The objective is to evaluate the optimal cross sectional areas $\left(A_{1}, A_{2}\right)$. The mathematical formulation is given as below:

Minimize: $f\left(A_{1}, A_{2}\right)=\left(2 \sqrt{2} A_{1}+A_{2}\right) \times H$,

where $H$ is shown in Figure 2 and it is equal to $100 \mathrm{~cm}$.

Subject to:

$$
\begin{aligned}
& g_{1}=\frac{\sqrt{2} A_{1}+A_{2}}{\sqrt{2} A_{1}^{2}+2 A_{1} A_{2}} P-\sigma \leq 0 \\
& g_{2}=\frac{A_{2}}{\sqrt{2} A_{1}^{2}+2 A_{1} A_{2}} P-\sigma \leq 0
\end{aligned}
$$

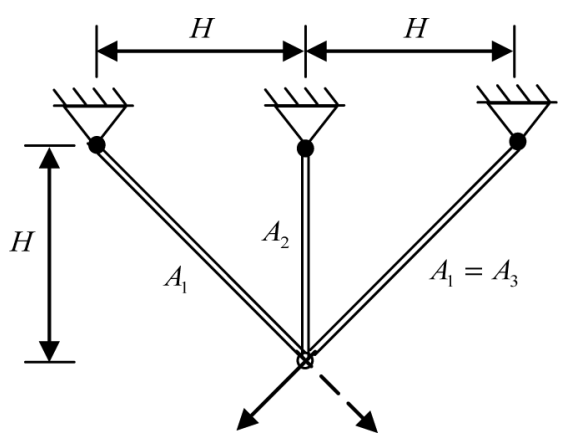

Fig. 2. Three bar truss

Table 3. Statistical results of the best three bar truss model

\begin{tabular}{lcccc}
\hline Best & Average & Median & Worst & S.D. \\
\hline 263.8932982 & 263.9465 & 263.8993 & 264.9561 & 0.16576 \\
\hline
\end{tabular}

$$
g_{3}=\frac{1}{A_{1}+\sqrt{2} A_{2}} P-\sigma \leq 0
$$

where:

$0 \leq A_{1} \leq 1$ and $0 \leq A_{2} \leq 1 ; l=100 \mathrm{~cm}, P=2 K \mathrm{~N} / \mathrm{cm}^{2}$, and $\sigma=2 K N / \mathrm{cm}^{2}$.

This design problem is a nonlinear fractional programming problem. The statistical values of the best solution obtained by the $\mathrm{KH}$ algorithm are given in Table 3. From this table, the optimized costs corresponding to worst and best designs are very close to each other.

The solution by KH is $\left(A_{1}, A_{2}\right)=(0.78867,0.40902)$ with the objective value equal to 263.97156 after 5,000 function evaluation in each run. Table 4 presents the solutions obtained by $\mathrm{KH}$ and those reported by other methods reported in the literature. As it is seen, the best objective value reported by Tsai (2005) is not feasible because the first constraint $\left(g_{1}\right)$ is violated. Hence, it can be concluded that the results obtained by KH are better than those of previous studies for this benchmark problem.

\subsection{Case III. Speed reducer design}

$\mathrm{KH}$ is applied to the design of a speed reducer which is a benchmark structural optimization problem (Gandomi, Yang 2011) (Fig. 3), with the face width (b), module of teeth $(m)$, number of teeth on pinion $(z)$, length of shaft 1 between bearings $\left(l_{1}\right)$, length of shaft 2 between bearings $\left(l_{2}\right)$, diameter of shaft $1\left(d_{1}\right)$, and diameter of shaft 2 $\left(d_{2}\right)$. The objective is to minimize the total weight of the speed reducer. The constraints involve limitations on the bending stress of the gear teeth, surface stress, transverse deflections of shafts 1 and 2 due to transmitted force, and stresses in shafts 1 and 2 .

The mathematical formulation can be summarized as minimizing the following function:

$$
\begin{aligned}
& f\left(b, m, z, l_{1}, l_{2}, d_{1}, d_{2}\right)=0.7854 b^{2}\left(3.3333 z^{2}+\right. \\
& 14.9334 z-43.0934)-1.508 b\left(d_{1}^{2}+d_{2}^{2}\right)+ \\
& 7.477\left(d_{1}^{3}+d_{2}^{3}\right)+0.7854\left(l_{1} d_{1}^{2}+l_{2} d_{2}^{2}\right) .
\end{aligned}
$$


Table 4. Best solutions for the three bar truss example

\begin{tabular}{lcccccccccccc}
\hline Ref. & $\begin{array}{c}\text { Gandomi } \\
\text { et al. } \\
(2013 \mathrm{~b})\end{array}$ & $\begin{array}{c}\text { Ray, } \\
\text { Saini } \\
(2001)\end{array}$ & $\begin{array}{c}\text { Zhang } \\
\text { et al. } \\
(2008)\end{array}$ & $\begin{array}{c}\text { Yang, } \\
\text { Gandomi } \\
(2012)\end{array}$ & $\begin{array}{c}\text { Zhao } \\
\text { et al. } \\
(2012)\end{array}$ & $\begin{array}{c}\text { Ray, } \\
\text { Liew } \\
(2003)\end{array}$ & $\begin{array}{c}\text { Wang } \\
\text { et al. } \\
(2009)\end{array}$ & $\begin{array}{c}\text { Wang, } \\
\text { Li } \\
(2010)\end{array}$ & $\begin{array}{c}\text { Tsai } \\
(2005)\end{array}$ & $\begin{array}{c}\text { Park } \\
\text { et al. } \\
(2007)\end{array}$ & $\begin{array}{c}\text { Rocha, } \\
\text { Fernandes } \\
(2009)\end{array}$ & $\begin{array}{c}\text { Present } \\
\text { Study }\end{array}$ \\
\hline Method & CS & PSO & DE $^{\mathrm{a}}$ & BA $^{\mathrm{b}}$ & $\mathrm{GA}$ & $\mathrm{SC}^{\mathrm{c}}$ & $\mathrm{EA}^{\mathrm{d}}$ & $\mathrm{DE}$ & $\mathrm{NLP}^{\mathrm{e}}$ & $\mathrm{NLP}^{\mathrm{N}}$ & $\mathrm{HEM}^{\mathrm{f}}$ & $\mathrm{KH}^{2}$ \\
\hline$A_{1}$ & 0.7887 & 0.795 & 0.78868 & 0.78863 & 0.78868 & 0.78862 & 0.35673 & 0.78868 & 0.788 & 0.78879 & 0.78876 & 0.78846 \\
$A_{2}$ & 0.4090 & 0.395 & 0.40825 & 0.40838 & 0.40825 & 0.40840 & 0.05169 & 0.40825 & 0.408 & 0.40794 & 0.40800 & 0.40882 \\
$g_{1}$ & -0.0003 & -0.0017 & 0.00000 & 0.00000 & -0.0000 & -0.0000 & -0.0000 & 0.00000 & $\mathbf{0 . 0 0 0 8}$ & -0.0000 & -0.0000 & 0.00000 \\
$g_{2}$ & -0.2685 & -0.2612 & -0.2680 & -0.2680 & -0.2680 & -0.2680 & -1.4641 & -1.4641 & -0.2674 & -0.2678 & -0.2678 & -0.2683 \\
$g_{3}$ & -0.7318 & -0.7404 & -0.7320 & -0.7320 & -0.7320 & -0.7320 & -0.5359 & -0.5359 & -0.7318 & -0.7322 & -0.7322 & -0.7317 \\
$f_{\min }$ & 263.97 & 264.3 & 263.896 & 263.896 & 263.896 & 263.896 & 263.896 & 263.896 & 263.68 & 263.897 & 263.896 & 263.893 \\
\hline
\end{tabular}

Notes: a DE is differential evolution; ${ }^{\mathrm{b}} \mathrm{BA}$ is bat algorithm; ${ }^{\mathrm{c} S C}$ is society and civilization; ${ }^{\mathrm{d}} \mathrm{EA}$ is evolutionary algorithm; ${ }^{\mathrm{e} N P}$ is non-linear programming; ${ }^{\mathrm{H}} \mathrm{Hybrid}$ electromagnetism like algorithm; ${ }^{\mathrm{g}}$ Violated set.

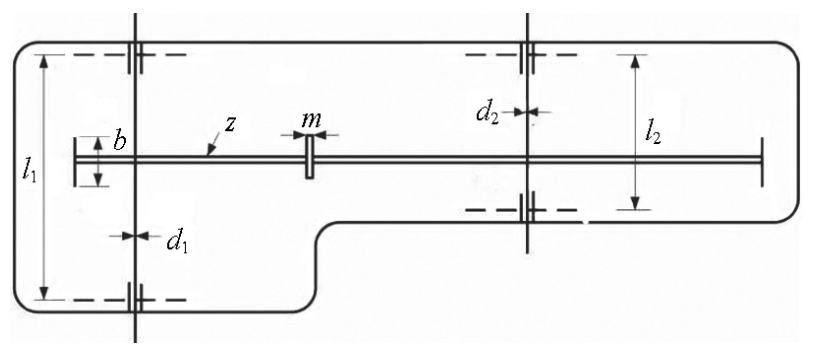

Fig. 3. Speed reducer

Subject to:

$$
\begin{gathered}
g_{1}=\frac{27}{b m^{2} z} P-1 \leq 0 ; \\
g_{2}=\frac{397.5}{b m^{2} z^{2}}-1 \leq 0 ; \\
g_{3}=\frac{1.93}{m z l_{1}^{3} d_{1}^{4}}-1 \leq 0 ; \\
g_{5}=\frac{\sqrt{\left(\frac{745 l_{1}}{m z}\right)^{2}+1.69 \times 10^{6}}}{110 d_{1}^{3}}-1 \leq 0 ; \\
\sqrt{\left(\frac{745 l_{1}^{3} d_{2}^{4}}{m z}\right)^{2}+157.5 \times 10^{6}} \\
g_{7}=\frac{m z}{40}-1 \leq 0 ; \\
\frac{\left(15 d_{2}^{3}\right.}{g_{4}}
\end{gathered}
$$

\begin{tabular}{|c|c|c|c|c|}
\hline Best & Average & Median & Worst & S.D. \\
\hline 2997.44677 & 3005.844 & 3006.244 & 3010.569 & 2.6337 \\
\hline \multicolumn{3}{|c|}{$g_{8}=\frac{m}{B-1}-1 \leq 0$} & & \\
\hline & & $\frac{b}{12 m}-1$ & & \\
\hline
\end{tabular}

Table 5. Statistical results of the speed reducer design example using $\mathrm{KH}$

where: $2.6 \leq b \leq 3.6,0.7 \leq m \leq 0.8,17 \leq z \leq 28,7.3 \leq$ $l_{1} \leq 8.3,7.8 \leq l_{2} \leq 8.3,2.9 \leq d_{1} \leq 3.9$, and $5.0 \leq d_{1} \leq 5.5$.

The corresponding statistical values of the Best $\mathrm{KH}$ model are presented in Table 5. From this table, the ratio between the optimized costs corresponding to worst and best designs is 1.00 and it shows $\mathrm{KH}$ algorithm has successfully found the optimum design in all runs.

Table 6 presents a comparison of the results obtained by $\mathrm{KH}$ and other methods. As it is seen, the $\mathrm{KH}$ results are better than those reported by Hsu and Liu (2007), Gandomi et al. (2013b), Akhtar et al. (2002), Montes et al. (2007), Efren et al. (2003), Michalewicz and Attia (1994), Hadj-Alouaneand Bean (1997), and Montes and Ocana (2008). Although the best objective values derived by Kuang et al. (1998), Li and Papalambros (1985), and Azarm and Li (1989) are better than those of KH, the reported values are not feasible. The result provided by Yang and Gandomi (2012) is best one and the results obtained in this study are the third best fitness value. It should be noted that some previous studies consider the simple bound of $l_{2}$ like $l_{1}$ so they are not considered in the comparison study.

\subsection{Case IV. Helical compression spring design}

Figure 4 shows a schematic representation of the helical compression spring design problem (Gandomi, Yang 2011). The spring is subject to an axially guided constant compression load. It must be designed for mini- 


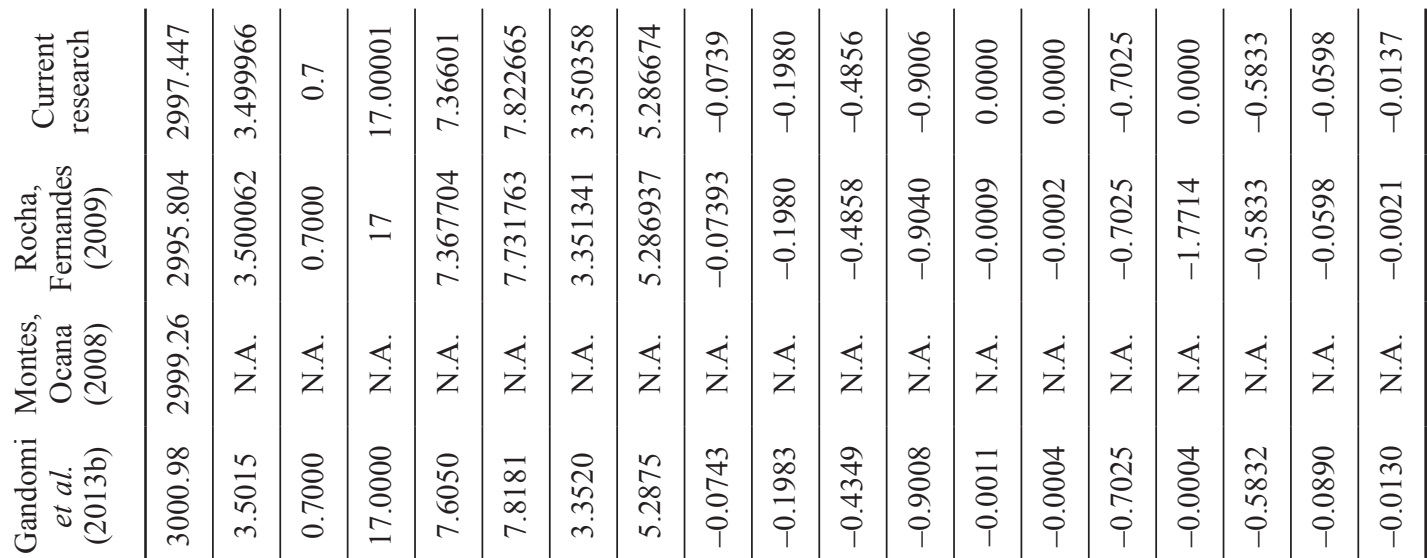

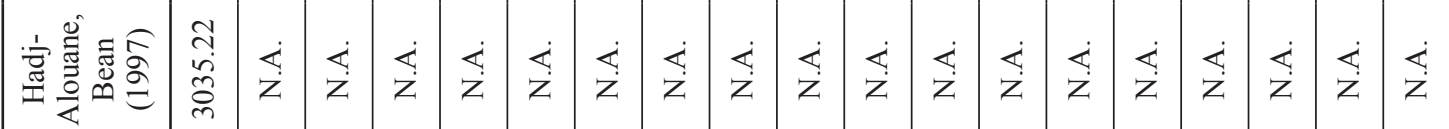

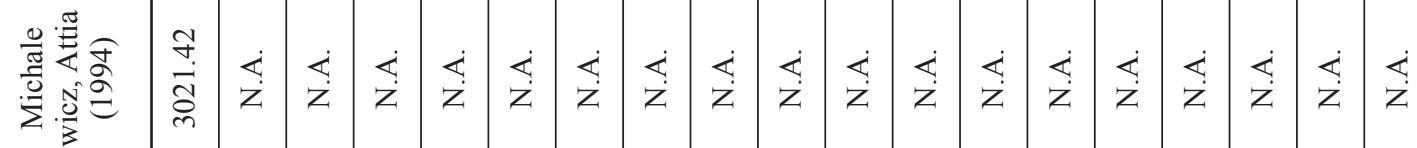

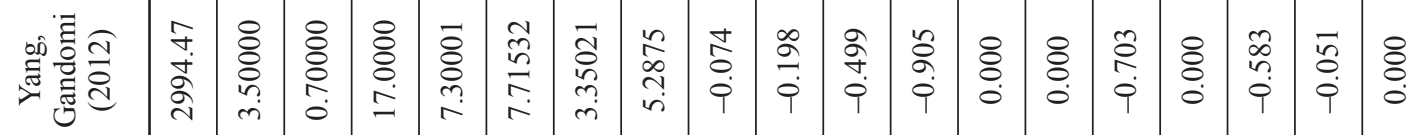

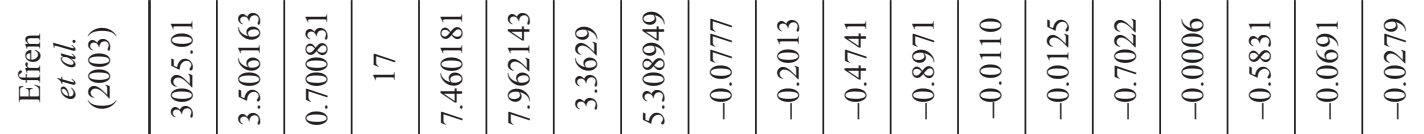

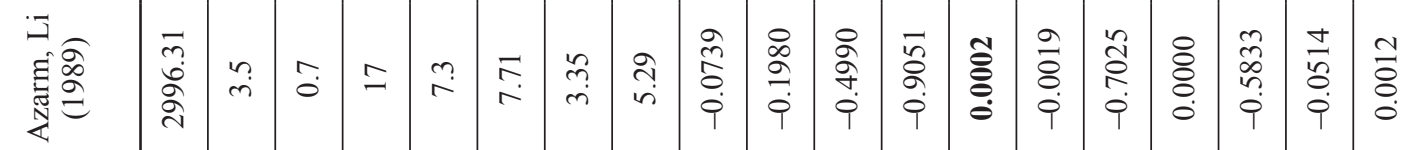

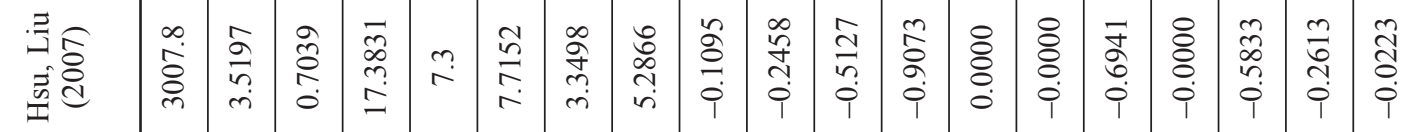

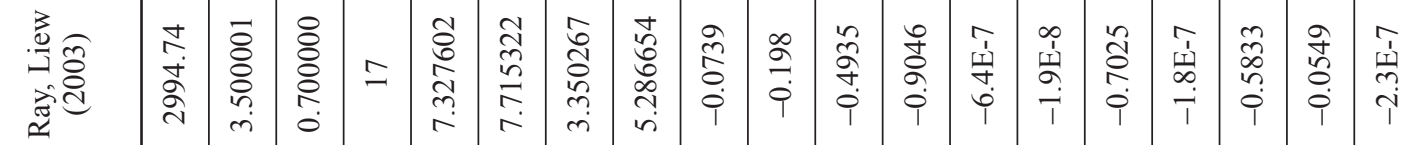

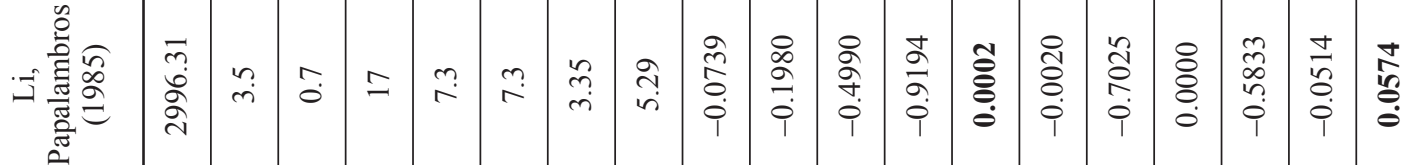

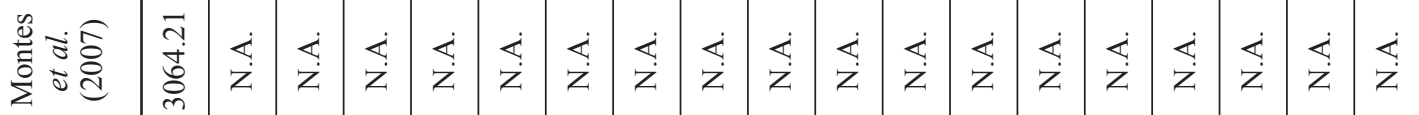

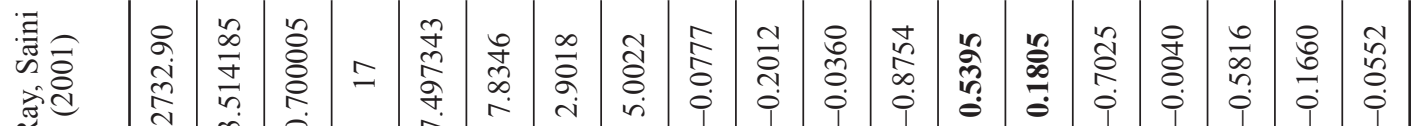
$\stackrel{\mathscr{E}}{\rightleftarrows}$

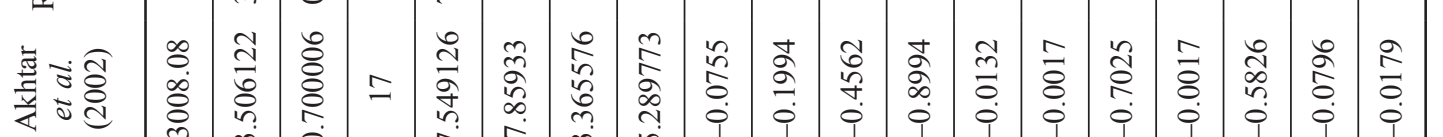

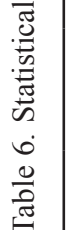

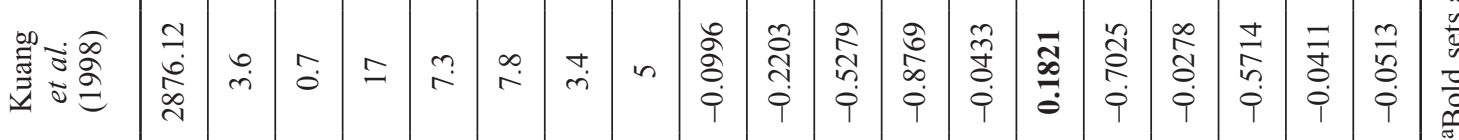

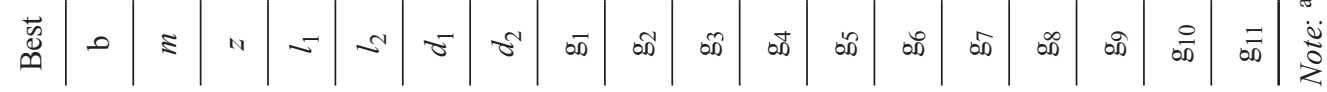




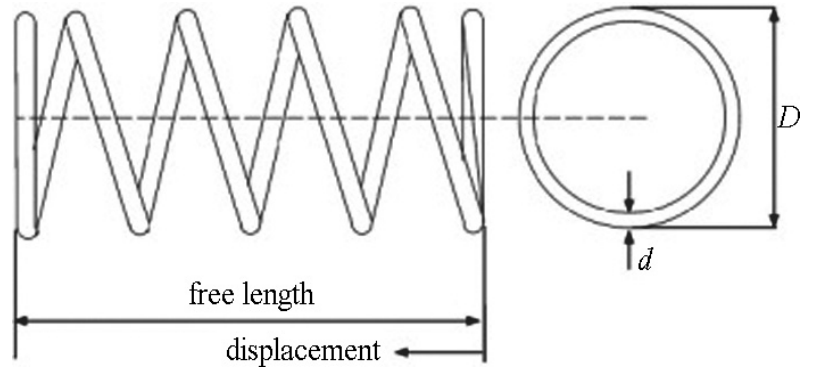

Fig. 4. Helical compression spring

Table 7. Discrete values of the spring wire diameters

\begin{tabular}{ccccccc}
\hline \multicolumn{7}{c}{$\mathrm{d}:$ Wire diameters (in.) } \\
\hline 0.009 & 0.0095 & 0.0104 & 0.0118 & 0.0128 & 0.0132 & 0.014 \\
\hline 0.015 & 0.0162 & 0.0173 & 0.018 & 0.020 & 0.023 & 0.025 \\
\hline 0.028 & 0.032 & 0.035 & 0.041 & 0.047 & 0.054 & 0.063 \\
\hline 0.072 & 0.080 & 0.092 & 0.105 & 0.120 & 0.135 & 0.148 \\
\hline 0.162 & 0.177 & 0.192 & 0.207 & 0.225 & 0.244 & 0.263 \\
\hline 0.283 & 0.307 & 0.331 & 0.362 & 0.394 & 0.4375 & 0.500 \\
\hline
\end{tabular}

mum volume. Spring ends are ground and squared. The parameters included are:

$D$ : winding coil diameter;

$d$ : wire diameter;

$n$ : number of spring coils.

$D$ is continuous, $n$ is an integer, and $d$ can take one of the 42 discrete values listed in Table 7 (Gandomi et al. 2011).

The design shear stress caused by the compression load should be lower than the allowable maximum shear stress $(S)$ of the material $\left(g_{1}\right)$. The free length of the spring should be shorter than the maximum specified value $L_{\text {free }}\left(g_{2}\right)$. The wire diameter must not be less than the specified minimum diameter $d_{\min }\left(g_{3}\right)$. The outerdiameter of the coil should be smaller than the specified maximum diameter $D_{\max }\left(g_{4}\right)$. The inner coil diameter must be at least three times less than the wire diameter to avoid a lightly wound spring $\left(g_{5}\right)$. The deflection under the given load $\delta$ must be less than the specified maximum deflection under preload $\delta_{p m}\left(g_{6}\right)$. The combined deflection must be consistent with the coil free length $L_{\text {free }}\left(g_{7}\right)$. The deflection from preload to maximum load must be greater than the specified working deflection $\delta_{w}\left(g_{8}\right)$. The cost function and constrained of the problem to be minimized are the spring volume, expressed as:

Minimize: $\quad f(D, d, n)=\frac{\pi D d^{2}(n+2)}{4}$.

Subjected to:

$$
\begin{gathered}
g_{1}=\frac{8 C_{f} P_{\max } D}{3.14156 d^{3}}-s \leq 0 \\
g_{2}=\frac{8 K P_{\max } D n}{C_{f} d^{4}}+1.05(n+2) d-L_{\text {free }} \leq 0 ; \\
g_{3}=d_{\min }-d \leq 0 ;
\end{gathered}
$$

$$
\begin{gathered}
g_{4}=(d+D)-D_{\max } \leq 0 ; \\
g_{5}=3-\frac{D-d}{d} \leq 0 ; \\
g_{6}=\delta-\delta_{p m} \leq 0 ; \\
g_{7}=\frac{8 K P_{\max } D^{3} n}{C_{f} d^{4}}+\frac{P_{\max -} P_{\text {load }}}{K}+1.05(n+2) \\
d-L_{\text {free }} \leq 0 ; \\
g_{8}=\delta_{W}-\frac{P_{\max }-P_{\text {load }}}{K} \leq 0,
\end{gathered}
$$

where:

$$
\begin{gathered}
C_{f}=\frac{4\left(S_{i}\right)-1}{4\left(S_{i}\right)-4}+\frac{0.615}{S_{i}} ; \\
S_{i}=\frac{D}{d} ; \\
K=\frac{G d^{4}}{8 n D^{3}} ; \\
\delta_{p}=\frac{F_{p}}{K} .
\end{gathered}
$$

The values assigned to constant terms involved in the spring design problem statement are listed in Table 8.

The optimization results obtained by $\mathrm{KH}$ are presented in Table 9. The optimization process was completed within 30,000 function evaluations. The ratio between the optimized costs corresponding to worst and best designs is 1.14 .

Table 10 compares the optimization results found by $\mathrm{KH}$ with similar data reported in literature. Whilst $\mathrm{KH}$

Table 8. Values of parameters involved in the formulation of the helical spring problem

\begin{tabular}{llc}
\hline Item & \multicolumn{1}{c}{ Description } & Values \\
\hline$P_{\max }$ & Maximum work load & $1000.0(\mathrm{lb})$ \\
\hline$S$ & Maximum shear stress & $189 \times 10^{3}(\mathrm{psi})$ \\
\hline$E$ & Elastic modulus of the material & $30 \times 10^{6}(\mathrm{psi})$ \\
\hline$G$ & Shear modulus of the material & $11.5 \times 10^{6}(\mathrm{psi})$ \\
\hline$L_{\text {free }}$ & Maximum coil free length & $14(\mathrm{in})$ \\
\hline$d_{\min }$ & Minimum wire diameter & $0.2(\mathrm{in})$ \\
\hline$D_{\max }$ & Maximum diameter of the spring & $3.0(\mathrm{in})$ \\
\hline$P_{\text {load }}$ & Preload compression force & $300.0(\mathrm{lb})$ \\
\hline$\delta_{p m}$ & $\begin{array}{l}\text { Maximum deflection under } \\
\text { preload }\end{array}$ & $6.0(\mathrm{in})$ \\
\hline$\delta_{w}$ & Deflection & $1.25(\mathrm{in})$ \\
\hline
\end{tabular}

Table 9. Statistical results of the $\mathrm{KH}$ optimization runs executed for the helical spring problem

\begin{tabular}{ccccc}
\hline Best & Mean & Median & Worst & S.D. \\
\hline 2.658553 & 2.745934 & 2.699644 & 3.040423 & 0.095919 \\
\hline
\end{tabular}


Table 10. Helical spring problem: comparison of $\mathrm{KH}$ results with literature

\begin{tabular}{ccccccccc}
\hline Reference & $\begin{array}{c}\text { Sandgren } \\
(1990)\end{array}$ & $\begin{array}{c}\text { Guo et al. } \\
(2004)\end{array}$ & $\begin{array}{c}\text { Wu, Chow } \\
(1995)\end{array}$ & $\begin{array}{c}\text { Fu } \text { et al. } \\
(1995)\end{array}$ & $\begin{array}{c}\text { Deb, Goyal } \\
(1997)\end{array}$ & $\begin{array}{c}\text { Yun } \\
(2005)\end{array}$ & $\begin{array}{c}\text { Gandomi } \\
\text { et al. }(2011)\end{array}$ & $\begin{array}{c}\text { Current } \\
\text { Study }\end{array}$ \\
\hline Method & N.A. & PSO & GA & NLP & GA & GA & FA & KH \\
\hline$d$ & 0.283 & 0.283 & 0.283 & 0.283 & 0.283 & 0.263 & 0.283 & 0.283 \\
$D$ & 1.180701 & 1.223 & 1.227411 & 1.2287 & 1.226 & 1.1096 & 1.223049 & 1.223038 \\
$N$ & 10 & 9 & 9 & 9 & 9 & 9 & 9 & 9 \\
$g_{1}$ & -5430.9 & -1008.81 & -550.993 & 415.969 & -713.51 & $\mathbf{2 5 1 5 4 . 8 2}$ & -1008.02 & -1009.13 \\
$g_{2}$ & -8.8187 & -8.946 & -8.9264 & 8.9207 & -8.933 & -9.1745 & -8.946 & -8.9456 \\
$g_{3}$ & -0.08298 & -0.083 & -0.0830 & 0.083 & -0.083 & -0.063 & -0.083 & -0.0830 \\
$g_{4}$ & -1.8193 & -1.77696 & -1.7726 & 1.7713 & -1.491 & -1.890 & -1.777 & -1.7770 \\
$g_{5}$ & -1.1723 & -1.3217 & -1.3371 & 1.3417 & -1.337 & -1.219 & -1.322 & -1.3217 \\
$g_{6}$ & -5.4643 & -5.4643 & -5.4485 & 5.4568 & -5.461 & -5.464 & -5.464 & -5.4643 \\
$g_{7}$ & 0 & 0 & 0 & 0 & 0 & 0 & 0 & 0.0000 \\
$g_{8}$ & 0.0000 & $\mathbf{0 . 0 0 0 1}$ & -0.0134 & 0.0174 & -0.0090 & -0.0014 & 0.0000 & 0.0000 \\
$f_{\text {min }}$ & 2.7995 & 2.659 & 2.6681 & 2.6709 & 2.665 & 2.0283 & 2.65858 & 2.65855 \\
\hline
\end{tabular}

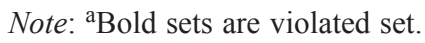

converged to the best design overall of 2.65855, some of the studies taken as reference found infeasible designs. It can be seen the $\mathrm{KH}$ solution is the best one in compare with the other methods.

\section{Conclusions}

The new $\mathrm{KH}$ algorithm is utilized to solve engineering optimization problems. The results indicate that the $\mathrm{KH}$ algorithm is very efficient for solving engineering problems. More, it performs superior to different existing algorithms. It can be because of this fact that there are fewer parameters to be fine-tuned in $\mathrm{KH}$ than in other algorithms. As agents generally contribute to the moving of each other based on their fitnesses, therefore the violated agents cannotaffect a lot on the others. In addition, a neighbour agent has an attractive/repulsive effect on the movement of the agent, therefore the neighbours with the better fitness, violated or not violated, attract the agent and other neighboursrepulse it. As an instance, if the agent isslightly violating the constraints, the agents with more violations repulse it and the feasible agents or agents with less violation attract the agent. These effects can act as an effective local search for each krill individual and the results generally prove it.

$\mathrm{KH}$ can be viewed as a system with multiple interacting Markov chains selected and biased towards global optimality. This powerful optimization method can be extended to study multi-objective optimization applications with various constraints, including NP-hard problems (Gandomi, Alavi 2012).

\section{References}

Akhtar, S.; Tai, K.; Ray, T. 2002. A socio-behavioural simulation model for engineering design optimization, Engineering Optimization 34(4): 341-354. http://dx.doi.org/10.1080/03052150212723

Azarm, S.; Li, W. C. 1989. Multi-Level design optimization using global monotonicity analysis, Journal of Mechanical Design ASME 111(2): 259-263.
Deb, K.; Goyal, M. 1997. Optimizing engineering designs using a combined genetic search, in $7^{\text {th }}$ International Conference on Genetic Algorithms, 19-23 July 1997, East Lansing, MI, USA, 512-528.

Efren, M.; Coello, C. A. C.; Ricardo, L. 2003. Engineering optimization using a simple evolutionary algorithm, in $15^{\text {th }}$ IEEE International Conference on Tools with Artificial Intelligence - ICTAI'2003, CA, USA, 3-5 November 2003, 149-156.

Fu, J. F.; Fenton, R. G.; Cleghorn, W. L. 1991. A mixed inegerdiscrete-continuous programming method and its application to engineering design optimization, Engineering Optimization 17(4): 263-280.

http://dx.doi.org/10.1080/03052159108941075

Gandomi, A. H.; Alavi, A. H. 2012. Krill Herd: a new bioinspired optimization algorithm, Communications in Nonlinear Science and Numerical Simulation 17(12): 4831-4845. http://dx.doi.org/10.1016/j.cnsns.2012.05.010

Gandomi, A. H.; Yang, X. S.; Alavi, A. H. 2011. Mixed variable structural optimization using firefly algorithm, Computers and Structures 89(23-24): 2325-2336. http://dx.doi.org/10.1016/j.compstruc.2011.08.002

Gandomi, A. H.; Yang, X.-S.; Talatahari, S.; Alavi, A. H. 2013a. Metaheuristic applications in structures and infrastructures. Elsevier: Waltham, MA.

Gandomi, A. H.; Yang, X. S.; Alavi, A. H. 2013b. Cuckoo search algorithm: a metaheuristic approach to solve structural optimization problems, Engineering with Computers 29(1): 17-35. http://dx.doi.org/10.1007/s00366-011-0241-y

Gandomi, A. H.; Alavi, A. H.; Talatahari, S. 2013c. Structural optimization using Krill Herd algorithm, in X. S. Yang et al. (Eds). Swarm intelligence and bio-inspired computation: theory and applications. Elsevier, 335-349. http://dx.doi.org/10.1016/B978-0-12-405163-8.00015-6

Gandomi, A. H.; Talatahari, S.; Tadbiri, F.; Alavi, A. H. 2013d. Krill Herd algorithm for optimum design of truss structures, International Journal of Bio-Inspired Computation 5(5): 281-288. http://dx.doi.org/10.1504/IJBIC.2013.057191

Gandomi, A. H.; Yang, X. S. 2011. Benchmark problems in structural optimization, in S. Koziel; X. S. Yang (Eds). Computational optimization, methods and algorithms. Berlin: Springer-Verlag, 267-291. http://dx.doi.org/10.1007/978-3-642-20859-1_12

Gandomi, A. H.; Yang, X. S.; Talatahari, S.; Deb, S. 2012. Coupled eagle strategy and differential evolution for unconstrained and constrained global optimization, Computers 
and Mathematics with Applications 63(1): 191-200. http://dx.doi.org/10.1016/j.camwa.2011.11.010

Guo, C. X.; Hu, J. S.; Ye, B.; Cao, Y. J. 2004. Swarm intelligence for mixed-variable design optimization, Journal of Zhejiang University Science 5(7): 851-860. http://dx.doi.org/10.1631/jzus.2004.0851

Hadj-Alouane, A. B.; Bean, J. C. 1997. A genetic algorithm for the multiple-choice integer program, Operations Research 45(1): 92-101. http://dx.doi.org/10.1287/opre.45.1.92

Hofmann, E. E.; Haskell, A. G. E.; Klinck, J. M.; Lascara, C. M. 2004. Lagrangian modelling studies of Antarctic krill (Euphasiasuperba) swarm formation, ICES Journal of Marine Science 61(4): 617-631.

http://dx.doi.org/10.1016/j.icesjms.2004.03.028

Hsu, Y.-L.; Liu, T.-C. 2007. Developing a fuzzy proportional derivative controller optimization engine for engineering design optimization problems, Engineering Optimization 39(6): 679-700. http://dx.doi.org/10.1080/03052150701252664

Kuang, J. K.; Rao, S. S.; Chen, L. 1998. Taguchi-aided search method for design optimization of engineering systems, Engineering Optmizations 30(1): 1-23. http://dx.doi.org/10.1080/03052159808941235

Li, H. L.; Papalambros, P. 1985. A production system for use of global optimization knowledge, Journal of Mechanical Design ASME 107: 277-284.

Michalewicz, Z.; Attia, N. 1994. Evolutionary optimization of constrained problems, in Proceedings of the $3^{\text {rd }}$ Annual Conference on Evolutionary Programming, World Scientific, 1994, River Edge, NJ, 98-108.

Montes, E. M.; Ocana, B. H. 2008. Modified bacterial foraging optimization for engineering design, in Proceedings of the $4^{\text {th }}$ Mexican Congress on Evolutionary Computation (COMCEV'2008), 27-31 October 2008, CIMAT, México, 33-38.

Montes, E.; Coello, C. A. C.; Velázquez-Reyes, J.; Muñoz-Dávila, L. 2007. Multiple trial vectors in differential evolution for engineering design, Engineering Optmization 39(5): 567589. http://dx.doi.org/10.1080/03052150701364022

Morin, A.; Okubo, A.; Kawasaki, K. 1988. Acoustic data analysis and models of krill spatial distribution, Selected Scientific Papers, Part I. Scientific Committee for the Conservation of Antarctic Marine Living Resources, 311-329.

Nowcki, H. 1974. Optimization in pre-contract ship design, in Y. Fujita; K. Lind; T. J. Williams (Eds). Computer applications in the automation of shipyard operation and ship design, Vol. 2. North-Holland, New York: Elsevier, 327-338.

Park, Y. C.; Chang, M. H.; Lee, T.-Y. 2007. A new deterministic global optimization method for general twice differentiable constrained nonlinear programming problems, Engineering Optimization 39(4): 397-411. http://dx.doi.org/10.1080/03052150701218475

Price, H. J. 1989. Swimming behavior of krill in response to algal patches: a mesocosm study, Limnol Oceanogr 34(4): 649-659. http://dx.doi.org/10.4319/lo.1989.34.4.0649

Rao, S. S. 1996. Engineering optimization: theory and practice. $3^{\text {rd }}$ ed. Chichester: John Wiley \& Sons.

Ray, T.; Saini, P. 2001. Engineering design optimization using a swarm with an intelligent information sharing among individuals, Engineering Optimization 33(6): 735-748. http://dx.doi.org/10.1080/03052150108940941

Ray, T.; Liew, K. M. 2003. Society and civilization: an optimization algorithm based on the simulation of social behavior, IEEE Transactions on Evolutionary Computation 7(4): 386-396. http://dx.doi.org/10.1109/TEVC.2003.814902

Rocha, A. M. A. C; Fernandes, E. M. G. P. 2009. Hybridizing the electromagnetism-like algorithm with descent search for solving engineering design problems, International Journal of Computer Mathematics 86(10-11): 1932-1946. http://dx.doi.org/10.1080/00207160902971533

Sandgren, E. 1990. Nonlinear integer and discrete programming in mechanical design optimization, Journal of Mechanical Design 112(2): 223-229. http://dx.doi.org/10.1115/1.2912596

Talbi, E. 2009. Metaheuristics: from design to implementation. Hoboken, New Jersey: John Wiley \& Sons. http://dx.doi.org/10.1002/9780470496916

Tsai, J. 2005. Global optimization of nonlinear fractional programming problems in engineering design, Engineering Optimization 37(4): 399-409. http://dx.doi.org/10.1080/03052150500066737

Wang, L.; Li, L. P. 2010. An effective differential evolution with level comparison for constrained engineering design, Structural and Multidisciplinary Optimization 41(6): 947-963. http://dx.doi.org/10.1007/s00158-009-0454-5

Wang, Y.; Cai, Z. X.; Zhou, Y. R.; Fan, Z. 2009. Constrained optimization based on hybrid evolutionary algorithm and adaptive constraint handling technique, Structural and Multidisciplinary Optimization 37(4): 395-413. http://dx.doi.org/10.1007/s00158-008-0238-3

Wu, S. J.; Chow, P. E. 1995. Genetic algorithms for nonlinear mixed discrete-integer optimization problems via metagenetic parameter optimizations, Engineering Optimization 24(2): 137-159. http://dx.doi.org/10.1080/03052159508941187

Yang, X.-S. 2009. Harmony search as a metaheuristic algorithm, in Z. W. Geem (Ed.). Music-inspired harmony search: theory and applications. New York: Springer, $1-14$.

Yang, X.-S. 2010. Nature-inspired metaheuristic algorithms. $2^{\text {nd }}$ ed. Bristol: Luniver Press.

Yang, X. S.; Gandomi, A. H. 2012. Bat algorithm: a novel approach for global engineering optimization, Engineering Computation 29(5): 464-483. http://dx.doi.org/10.1108/02644401211235834

Yun, Y. S. 2005. Study on adaptive hybrid genetic algorithm and its applications to engineering design problems: MSc thesis. Waseda University.

Zhang, M.; Luo, W.; Wang, X. 2008. Differential evolution with dynamic stochastic selection for constrained optimization, Information Sciences 178(15): 3043-3074. http://dx.doi.org/10.1016/j.ins.2008.02.014

Zhao, J.; Wang, L.; Zeng, P.; Fan, W. 2012. An effective hybrid genetic algorithm with flexible allowance technique for constrained engineering design optimization, Expert Systems with Applications 39(5): 6041-6051. http://dx.doi.org/10.1016/j.eswa.2011.12.012

Amir H. GANDOMI. He graduated in Civil and Structural Engineering from Iran University of Science \& Technology and Tafresh University. He is currently a Researcher in the Department of Civil Engineering at the University of Akron, OH, USA. He is pioneer of Krill Herd algorithm and has published over 100 research papers and book chapters. He has two patents and has published three books in Elsevier. His research interests are intelligent modelling and optimization.

Amir H. ALAVI. He graduated in Civil and Geotechnical Engineering from Iran University of Science \& Technology. He is currently a researcher in Department of Civil \& Environmental Engineering at Michigan State University, MI, USA. He is pioneer of Krill Herd algorithm and has published over 100 research papers and book chapters. He has two patents and has published two books in Elsevier. His research interests are civil engineering modelling and optimization. 